\title{
PENGARUH PIJAT TUI NA TERHADAP STATUS PERTUMBUHAN PADA BALITA DENGAN STATUS KMS T
}

\author{
Annif Munjidah, Fitria Dwi A \\ Universitas Nahdlatul Ulama Surabaya, annifmunjidah@unusa.ac.id
}

\begin{abstract}
Abstrak
Satu dari tiga balita mengalami gangguan pertumbuhan (bayi pendek untuk rata-rata usianya / stunted) dan hampir seperlima jumlah balita mengalami mengalami berat badan kurang di bawah standar ratarata (underweight). (UNICEF, 2011). Penyebab masalah gizi di perkotaan umumnya disebabkan oleh gangguan penyerapan makanan. Hal ini bisa diatasi dengan pijat Tui Na. Tujuan penelitian ini untuk mengetahui pengaruh pijat tui na terhadap status pertumbuhan pada balita dengan status KMS T di Kelurahan Wonokromo Surabaya. Penelitian ini menggunakan Quasi Eksperimental dengan desain after and before with control design. Populasi penelitian ini adalah seluruh balita dengan status KMS T. Sampel diambil dengan simple random sampling, didapatkan besar sampel 26 orang. Waktu penelitian pada februari-Juli 2018. Pijat Tui Na diterapkan berdasarkan standar operasional prosedur (SOP). Lembar observasi digunakan untuk mengumpulkan data secara langsung yang dianalisis dengan menggunakan uji paired t-test dan independent $t$ test. Uji analisis pengaruh before - after pijat tui na menggunakan uji paired $t$-test didapatkan nilai $\mathrm{P}=0,019<\alpha=0,05$ Sedangkan pada kelompok kontrol dan perlakuan menggunakan uji independent t-test dan didapatkan hasil nilai $\mathrm{P}=0,065>\alpha=$ 0,05. Ada pengaruh pijat tui na terhadap status pertumbuhan pada balita dengan status KMS T. Berdasarkan hal tersebut bidan diharapkan dapat menerapkan pijat Tui $\mathrm{Na}$ sebagai salah satu upaya dalam mengatasi status pertumbuhan pada balita dengan status KMS T.
\end{abstract}

Kata kunci: Pijat Tui Na, status pertumbuhan, anak

\section{PENDAHULUAN}

Setiap orang tua menginginkan anaknya tumbuh dengan normal. Pertumbuhan (growth) yaitu berkaitan dengan masalah perubahan dalam besar jumlah, ukuran atau dimensi tingkat sel, organ maupun individu, yang bisa diukur dengan ukuran berat dan panjang (Soetjiningsih, 2008). Pertumbuhan yang baik akan menjadi modal bagi kelangsungan anak sebagai generasi penerus bangsa, sebaliknya ia juga dapat sebagai penghambat kelangsungan generasi penerus (Aziz dkk, 2005).

Masalah pertumbuhan di Indonesia masih lekat dengan gizi kurang dan obesitas. Di Indonesia jutaan anak berusia di bawah lima tahun mengalami masalah gizi ini. (Kemenkes, 2016)

UNICEF menemukan jutaan anak di Asia Tenggara dan Asia Selatan masih megalami masalah gizi. Satu dari tiga balita mengalami gangguan pertumbuhan (bayi pendek untuk rata-rata usianya / stunted) dan hampir seperlima jumlah balita mengalami mengalami berat badan kurang dibawah standar rata-rata (underweight) (UNICEF, 2011). Menurut hasil Data Riset Kesehatan Dasar tahun 2013 mencatat bahwa 18,8\% balita mengalami masalah gizi yakni kurang gizi dan 29\% mengalami stunting (tubuh pendek). Angka prevalensi ini di atas 
ambang batas yang disepakati secara universal, batas non public health problem yang ditolerir oleh badan kesehatan dunia (WHO) yakni hanya 20\% atau seperlima dari jumlah total balita di suatu negara.

Masalah gizi kurang adalah suatu keadaan dimana berat badan berada di bawah kurva pertumbuhan WHO, sedangkan stunting adalah keadaan dimana anak dikatakan gagal tumbuh akibat kekurangan gizi dan penyakit berulang dalam waktu lama pada masa janin hingga 2 tahun pertama kehidupan seorang anak (Kemenkes, 2010). Beberapa faktor penyebab masalah gizi yaitu: faktor keterbatasan penghasilan keluarga (ekonomi), pengetahuan kesehatan akan gizi makanan, jarak Kelahiran, prasangka buruk terhadap makanan tertentu, tradisi pantangan yang merugikan, dan kesukaan yang berlebihan akan makanan tertentu. Namun, penyebab masalah gizi di perkotaan bukan karena faktor ekonomi namun didominasi oleh gangguan penyerapan makanan.

Kurang gizi dan berat badan saat balita akan berpengaruh terhadap perkembangan saat dewasa menjadi tidak maksimal baik dalam hal kesehatan maupun mental. Sedangkan anak dengan stunting beresiko memiliki IQ 5-10 poin lebih rendah dibanding dengan anak yang normal (Yenni Puspita, 2015).
Untuk itu diperlukan upaya yang dapat mengatasi masalah gangguan pertumbuhan ini melalui pendekatan untuk mengatasi kesulitan makan dan meningkatkan daya penyerapan zat gizi yang bersifat savety dan meminimalkan dampak buruk pada anak. Dewasa ini telah dikembangkan dari tehnik pijat bayi, yakni pijat Tui Na. Pijat ini dilakukan dengan tehnik pemijatan meluncur (Effleurage atau Tui), memijat (Petrissage atau Nie), mengetuk (tapotement atau Da), gesekan, menarik, memutar, menggoyang, dan menggetarkan titik tertentu sehingga akan mempengaruhi aliran energi tubuh dengan memegang dan menekan tubuh pada bagian tubuh tertentu. Pijat Tui Na ini merupakan tehnik pijat yang lebih spesifik untuk mengatasi kesulitan makan pada balita dengan cara memperlancar peredaran darah pada limpa dan pencernaan.

Hasil penelitian Zhen Huan Liu dan Li Ting Cen di Guangzhou tahun 2009 menyebutkan bahwa pijat Tui na berpengaruh positif terhadap perkembangan syaraf dan peredaran darah pada bayi (Zhuan Huan Liu, 2011). Penelitian serupa juga dilakukan oleh Joko Widodo dkk (2012) didapatkan bahwa pijat $\mathrm{Tui} \mathrm{Na}$ dapat memperlancar aliran darah ke pencernaan dan limpa yang dapat meningkatkan daya absorbsi zat gizi. 
Wonokromo merupakan salah satu kelurahan di Kota Surabaya, yang memiliki masyarakat heterogen, kegiatan dan pelayanan kesehatan di Wonokromo cukup baik, sejak tahun 2015. Peneliti mengambil daerah ini sebagai daerah binaan dalam lingkup 1 RW yakni RW 02. Pada tahun 2016, peneliti mendapatkan data dari posyandu balita yang ada di RW 02 Kelurahan Wonokromo bahwa disana memiliki permasalahan yang khas yakni ada 2 atau lebih balita dalam satu KK, sebagian besar ibu tidak menggunakan alat kontrasepsi, artinya jarak kelahiran cukup dekat. Kemudian pada tahun 2017 peneliti melakukan koordinasi dengan petugas Gizi Puskesmas Wonokromo mengenai gizi balita di Wonokromo dan hasilnya cukup mengejutkan, terdapat 38 balita dengan status gizi kurang, 1 orang di antaranya karena mengalami kelainan bawaan, 2 balita pindah tempat tinggal dan 35 balita lainnya tinggal menetap di kelurahan Wonokromo. Saat itu peneliti melakukan pendampingan berupa penyuluhan dan demonstrasi terkait gizi kurang yang dikemas dalam kegiatan pengabdian masyarakat, terlihat saat kegiatan posyandu gizi berlangsung sebagian balita tidak mau makan saat diberi makanan tambahan, sebagian lagi terlihat lahap dalam menyantap makanan tambahan, hal tersebut menyebabkan rasa keingintahuan peneliti untuk mengkaji lebih lanjut tentang pengaruh pijat $\mathrm{Tui} \mathrm{Na}$ terhadap kenaikan berat badan balita. Oleh karena itu penulis merasa perlu untuk menganalisis pengaruh pijat $\mathrm{Tui} \mathrm{Na}$ terhadap status pertumbuhan pada balita dengan status KMS T.

\section{METODE}

Jenis penelitian yang digunakan adalah jenis penelitian pra experimental dengan bentuk rancangan Quasi Eksperimental dengan desain after and before with control design. Observasi akan dilakukan setelah pemberian perlakuan pada 2 (dua) kelompok yaitu: kelompok perlakuan dan kelompok kontrol.

Penelitian dilakukan dengan memberikan intervensi pada kelompok eksperimen yakni berupa pijat Tui Na pada bagian tubuh jari-jari, tangan, kaki, punggung dan perut responden, perlakuan pada kelompok ini diberikan selama 4 siklus, tiap siklusnya selama 6 hari berturut-turut tanpa jeda oleh tim peneliti. Sedangkan pada kelompok kontrol yakni berupa Effleurage atau usapan pada bagian yang sama seperti bagian tubuh pijat Tui $\mathrm{Na}$ yakni: jari-jari, tangan, kaki, punggung dan perut. Pemberian Effleurage pada kelompok control ini juga diberikan selama 4 siklus, tiap siklusnya 6 hari berturut-turut oleh tim peneliti. Sebelum dilakukan intervensi pijat $\mathrm{Tui} N \mathrm{Na}$ dan 
Effleurage, Berat Badan Balita ditimbang sebagai data pretest. Sesudah dilakukan intervensi pijat Tui $\mathrm{Na}$ dan Effleurage, pengukuran Berat Badan (BB) kembali dilakukan pada balita sebagai data post test Populasi pada penelitian ini adalah seluruh balita dengan status KMS T di Wonokromo Surabaya. Dengan simple random sampling didapatkan besar sample 26 orang.

Penelitian dilakukan di Wonokromo Surabaya. Dilaksanakan pada bulan februari - Juli 2018. Peneliti mengajukan permohonan penelitian ke Bakesbang Surabaya, Kecamatan dan Kelurahan Wonokromo juga Komisi etik penelitian (KEPK) UNUSA. Sebelum peneliti melakukan pengambilan data peneliti melakukan koordinasi dengan puskesmas dan Kader Posyandu Wonokromo. Selain itu peneliti juga meminta kesediaan dan informed consent kepada responden

Instrumen penelitian untuk variabel pelaksanaan pijat Tui $\mathrm{Na}$ menggunakan SOP dan, sedangkan untuk mengukur variabel dependen status pertumbuhan yakni timbangan berat badan. Pengumpulan data dilakukan secara langsung / data primer, dan dianalisis dengan uji paired t-test dan independent ttes

\section{HASIL}

Hasil pengumpulan data didapatkan 26 responden, masing-masing 13 responden untuk kelompok kontrol dan 13 responden untuk kelompok perlakuan. Berdasarkan pengkajian yang dilakukan pada dua kelompok sebelum dilakukan perlakuan didapatkan data mengenai karakteristik responden meliputi usia balita dan jenis kelamin yang disajikan dalam tabel 5.1 sebagai berikut.

Tabel 1 Karakteristik responden penelitian pengaruh pijat $\mathrm{Tui} \mathrm{Na}$ terhadap status pertumbuhan pada balita dengan status KMS T

\begin{tabular}{lcccc}
\hline Karakteristik & $\begin{array}{c}\text { Kelompok } \\
\text { kontrol }\end{array}$ & $\begin{array}{c}\text { Kelompok } \\
\text { perlakuan }\end{array}$ & $\begin{array}{c}\text { Frekuensi } \\
\text { (f) }\end{array}$ & $\begin{array}{c}\text { Persentase } \\
(\%)\end{array}$ \\
\hline Usia Balita & & 3 & 5 & 19,2 \\
6 bln s/d 3 th & 2 & 10 & 21 & 80,8 \\
3 s/d 5 th & 11 & 13 & 26 & 100 \\
\hline Total & 13 & 6 & 11 & 42,3 \\
\hline Riwayat ASI & 5 & 7 & 15 & 57,6 \\
ASI & 8 & & & \\
Eksklusif & & 13 & & \\
Non ASI & & & & \\
Eksklusif & 13 & 100 \\
\hline Total & \multicolumn{4}{c}{ Sumber: data primer April 2018 }
\end{tabular}

Diketahui dari tabel 1 bahwa hampir seluruh responden berusia 3 tahun sampai 5 tahun. Pada usia ini sebenarnya anak sudah mulai memasuki masa pra sekolah, dengan aktivitas yang banyak anak akan merasa lapar dan tidak segan untuk meminta makan pada orang tua, hal tersebut sejalan dengan teori Afiani Lika dkk (2003) bahwa kesulitan makan sering dialami oleh anak usia 1-3 tahun. Pada 
karakteristik riwayat pemberian ASI Eksklusif hampir setengah responden mendapat ASI Eksklusif. Peran ASI Eksklusif sangat penting berkaitan dengan fungsi pencernaan dan penyerapan nutrisi oleh bayi sampai dengan usia 6 bulan. Hal tersebut sejalan dengan Hegar Badriul (2013) dalam buku bedah ASI IDAI tahun bahwa proses maturisasi saluran cerna distmulasi oleh ASI yang difasilitasi oleh kolostrum.

Tabel 2 Hasil statistik deskriptif status pertumbuhan balita sebelum diberi perlakuan.

\begin{tabular}{cccc}
\hline Berat badan balita & Mean & Median & Modus \\
\hline Kelompok kontrol & 9,3 & 10 & 10,0 \\
\hline Kelompok perlakuan & 10,4 & 10,5 & 7,8
\end{tabular}

Sumber: data primer April 2018

Diketahui dari tabel 2 bahwa rerata berat badan balita sebelum dilakukan pemijatan pada kelompok kontrol yakni 9,3 kg dan pada kelompok perlakuan sebesar 10,4 kg.

Tabel 3 Distribusi frekuensi status pertumbuhan balita setelah diberi perlakuan pada kelompok kontrol dan kelompok perlakuan

\begin{tabular}{cccccc}
\hline $\begin{array}{c}\text { Status } \\
\text { Pertumbuhan }\end{array}$ & Naik & $\begin{array}{c}\text { Persenta } \\
\text { se }(\%)\end{array}$ & $\begin{array}{c}\text { Tidak } \\
\text { Naik }\end{array}$ & $\begin{array}{c}\text { Persentase } \\
(\%)\end{array}$ & Total \\
\hline $\begin{array}{c}\text { Kelompok } \\
\text { control }\end{array}$ & 5 & 38,5 & 8 & 61,5 & $\begin{array}{c}13 \\
(100)\end{array}$ \\
\hline $\begin{array}{c}\text { Kelompok } \\
\text { perlakuan }\end{array}$ & 10 & 76,9 & 3 & 23,1 & $\begin{array}{c}13 \\
(100)\end{array}$ \\
\hline
\end{tabular}

Sumber: Data Primer, Mei 2018

Diketahui dari tabel 3 bahwa setelah dilakukan pijat $\mathrm{Tui} \mathrm{Na}$ hampir seluruh $(76,9 \%)$ balita mengalami kenaikan berat badan, sedangkan pada kelompok kontrol hampir setengahnya $(38,5 \%)$ mengalami kenaikan berat badan

Tabel 4 Hasil uji analisis pengaruh pijat Tui Na terhadap status pertumbuhan pada balita dengan status KMS T

\begin{tabular}{cc}
\hline Kelompok responden (Metode uji) & $\begin{array}{c}\text { Nilai Sig } \\
(2 \text {-tailed) }\end{array}$ \\
\hline Before-after (paired t test) & 0,019 \\
\hline Effleurage-Tui Na (independent t test) & 0,065 \\
\hline Sumber: Data Primer, 2018 &
\end{tabular}

Sumber: Data Primer, 2018

Hasil uji analisis pengaruh before (sebelum) - after (sesudah) pijat tui na menggunakan uji paired $t$-test menyatakan nilai $\mathrm{P}=0,019$. Hal tersebut menunjukkan bahwa nilai sig $<\alpha(0,05)$ yang berarti terdapat pengaruh yang signifikan antara status pertumbuhan balita dengan status KMS $\mathrm{T}$ sebelum dan sesudah diberi perlakuan pijat tuina. Sedangkan hasil uji analisis kelompok kontrol dan perlakuan menggunakan independent sample t-test menunjukkan hasil nilai $\mathrm{P}=0,065$. Hasil tersebut menunjukkan bahwa nilai sig $>\alpha$ $(0,05)$ yang berarti $\mathrm{H}_{0}$ diterima, yang artinya tidak terdapat pengaruh yang signifikan antara kelompok perlakuan pijat tui na dengan kelompok kontrol effleurage (pengusapan) dengan status pertumbuhan balita dengan status KMS T.

\section{PEMBAHASAN}

Pembahasan pengaruh pijat Tui $N a$ terhadap status pertumbuhan pada balita: 
1. Pengaruh perlakuan pijat tui na terhadap status pertumbuhan pada balita dengan status KMS $\mathrm{T}$ sebelum dan sesudah dilakukan pijat tui na. Dari hasil analisis diinformasikan bahwa status pertumbuhan balita KMS T dipengaruhi oleh pijat tui na. Pada kelompok perlakuan pijat tui na sebagian besar ibu balita mengatakan bahwa setelah dipijat anak tidur lelap, sering lapar dan frekuensi makannya lebih sering dibandingkan sebelum dipijat. Hal ini sesuai dengan teori tentang aktivitas Nervus vagus yang mempengaruhi mekanisme penyerapan makanan. Pada balita yang dipijat akan menyebabkan peningkatan tonus saraf vagus. Penelitian Field dan Schanberg (1986) menunjukkan bahwa pada anak yang dipijat mengalami peningkatan tonus ini, sehingga cabang saraf vagus (saraf otak ke 10) akan menyebabkan peningkatan kadar enzim penyerapan gastric dan insulin. Dengan demikian penyerapan makanan akan menjadi lebih baik (Roesli, 2011).

Pijat tui na juga merupakan salah satu penatalaksanaan non farmakologis yang dapat meningkatkan nafsu makan, mengurangi rasa "enggan" makan dan mual muntah. Salah satu kelebihan pijat tui na dibanding dengan pijat lainnya adalah kemampuannya yang fokus pada masalah spesifik dan tidak hanya bekerja pada otot, tulang, dan sendi, namun juga bekerja dengan energi tubuh pada tingkat yang lebih dalam sehingga dapat menjaga energi tubuh dalam keseimbangan. Selain itu pijat tui na memiliki efek samping yang jauh lebih sedikit dibandingkan dengan perawatan modern berdasarkan obat kimia. Hal ini sesuai degan teori Sukanta (2010) bahwa pijat Tui Na merupakan tehnik pijat yang lebih spesifik dengan cara memperlancar peredaran darah pada limpa dan pencernaan, melalui modifikasi dari akupunktur tanpa jarum. Teknik ini menggunakan penekanan pada titik meridian tubuh atau garis aliran energi sehingga relatif lebih mudah dilakukan dibandingkan akupuntur. Pijat tui na terdiri dari 8 langkah, diberikan pada anak setiap hari selama 6 hari berturut-turut, pada penelitian ini responden mendapatkan pijat secara kontinu selama 4 (empat) minggu berturutturut.

Responden yang telah mendapatkan pemijatan selama 4 siklus pijat Tui $\mathrm{Na}$ terlihat semakin sering meminta makan pada ibu yang akhirnya berdampak positif terhadap peningkatan status pertumbuhan, dalam hal ini peningkatan berat badan (BB). Penelitian tentang efek pijat dan kenaikan berat badan juga dilakukan oleh Sofiani (2011) tentang pengaruh pijat terhadap pertumbuhan, yang menunjukkan bahwa setelah dilakukan pijat bayi teratur 
setiap 2 kali dalam 1 minggu selama 5 minggu oleh orang tua masing-masing bayi didapatkan hasil bahwa sebagian besar bayi mengalami peningkatan berat badan sebesar lebih dari sama dengan 1000 gram yang dilakukan pada 11 bayi. Selain itu juga ada penelitian dari Dieter at al (2003) yang meneliti tentang efek pijat, ia memberikan pijatan sebanyak 3x dengan durasi tiap pijatan selama 15 menit setiap hari selama 5 hari pada bayi prematur. Hasilnya terdapat rerata peningkatan berat badan 53\% lebih besar dibanding pada kelompok kontrol yang tidak dipijat. Hal tersebut juga selaras dengan hasil penelitian Amelia Yuliana dkk tahun 2013 di Kelurahan Tawanganom Magetan. Yang menunjukkan hasil penelitian terdapat perbedaan berat badan bayi usia 3-5 bulan antara sebelum dan sesudah dilakukan pemijatan.

2. Hasil uji analisis status pertumbuhan setelah dilakukan perlakuan pada kelompok kontrol (Effleurage) dengan kelompok perlakuan (pijat tui na).

Status pertumbuhan balita KMS T tidak dipengaruhi oleh pijat Tui Na pada kelompok kontrol (effleurage) dan kelompok perlakuan (pijat tui na). Pijat tui na merupakan serangkaian gerakan memijat yang dilakukan dengan tehnik pemijatan meluncur (Effleurage atau Tui), memijat (Petrissage atau Nie), mengetuk
(Tapotement atau $D a$ ), gesekan, menarik, memutar, menggoyang, dan menggetarkan titik tertentu sehingga akan mempengaruhi aliran energi tubuh dengan memegang dan menekan tubuh pada bagian tubuh tertentu (Sukanta, 2010) sedangkan effleurage (pijat ringan) adalah salah satu gerakan utama dalam pijat dan bisa dilakukan di bagian tubuh manapun. Teknik effleurage bertujuan untuk meningkatkan sirkulasi darah, memberi tekanan, dan menghangatkan otot abdomen serta meningkatkan relaksasi fisik dan mental. Effleurage merupakan teknik massage yang aman, mudah untuk dilakukan, tidak memerlukan banyak alat, tidak memerlukan biaya, tidak memiliki efek samping dan dapat dilakukan sendiri atau dengan bantuan orang lain (Ekowati, 2011).

Pada kelompok perlakuan dan kelompok komtrol penelitian ini tidak terbukti bahwa pijat Tui $\mathrm{Na}$ berpengaruh terhadap status pertumbuhan balita yang artinya bahwa ada faktor dominan yang mempengaruhi pertumbuhan fisik seseorang yaitu faktor genetik dan faktor lingkungan. Kemampuan genetis dapat muncul secara optimal jika didukung oleh faktor lingkungan yang kondusif, yang dimaksud dengan faktor lingkungan disini adalah intake gizi. Tiga tahun pertama kehidupan anak merupakan masa yang sangat penting 
karena terjadi pertumbuhan fisik dan perkembangan (kecerdasan, keterampilan motorik, mental, sosial, emosional) yang sangat pesat (Adroeni, 2010). Selain pijat bayi, faktor pemenuhan nutrisi bisa mempengaruhi pertumbuhan bayi dan mempengaruhi hormon pertumbuhan tersebut. Pertumbuhan bayi mungkin juga dapat dikarenakan oleh faktor genetik, kesehatan anak, imunisasi, perumahan, sanitasi lingkungan, kelainan kromosom, sosio-ekonomi, dan obat-obatan. Dari beberapa faktor tersebut ada dua faktor yang tidak dapat dikendalikan yaitu perumahan dan sanitasi lingkungan, dimana kedua faktor tersebut kemungkinan memberikan kontribusi dalam pertumbuhan bayi. Stimulasi atau rangsangan yang baik untuk anak dapat diberikan oleh orang tua untuk perkembangan potensinya secara maksimal. Hal tersebut selaras dengan teori yang menyebutkan bahwa faktor yang berhubungan dengan tumbuh kembang anak yaitu nutrisi yang tercukupi, lingkungan keluarga yang mendukung merupakan dasar untuk tumbuh kembang anak. (Adriana, 2013).

\section{SIMPULAN}

Dari hasil penelitian yang dilakukan, maka peneliti menyimpulkan beberapa hal sebagai berikut:
1. Pijat Tui na mempengaruhi status pertumbuhan pada balita dengan status KMS T sebelum dan sesudah dilakukan pijat tui na

2. Pijat Tui na tidak mempengaruhi status pertumbuhan pada balita dengan status KMS T pada kelompok kontrol dan kelompok perlakuan

3. Ada pengaruh pemberian pijat tui na terhadap status pertumbuhan balita dengan status KMS T.

\section{DAFTAR RUJUKAN}

Adriana, D. 2013. Tumbuh Kembang dan Terima Bermain pada Anak. Jakarta: Salemba Medika.

Adroeni, M. 2010. Pengaruh Pijat Bayi terhadap Kenaikan Berat Badan Bayi Umur 0-3 Bulan di BPS Saraswati Sleman Yogyakarta Tahun. Skripsi.

Aziz Alimul Hidayat. Musrifatul Uliyah. 2005. Kebutuhan Dasar Manusia. Jakarta: Penerbit Buku Kedokteran

Ekowati, R., Wahjuni, E. S., \& Alifa, A. 2011. Efek Teknik Masase Effleurage pada Abdomen terhadap Penurunan Intensitas Nyeri pada Disminore Primer Mahasiswi PSIK FKUB Malang. Malang: Poltekes Malang

Hegar Badriul dkk. 2013. Buku Bedah ASI IDAI www.idai.or.id akses 08 Juli 2018 jam 15.00 http://pickyeatersclinik.com akses 27 Mei 2016 jam 11.00

Ika, Afiani L.dkk. 2003. Ramuan jamu cekok sebagai penyembuhan kurang nafsu makan pada anak. Jurnal Makara kesehatan, Vol. 7, No 1, Juni 2003. UGM: Yogyakarta

Kemenkes RI. 2016. Pemantauan status gizi dilakukan di seluruh kabupaten / kota di Indonesia tahun 2015. www.depkes.go.id

Puspita, Yenni. 2015. Faktor dan dampak 
stunting pada kehidupan balita. Dinas Kesehatan Provinsi Bengkulu. Word Press.

Roesli Utami. 2011. Pedoman pijat bayi. Edisi revisi XIII. Jakarta: tribulus Agriwidya

Soetjiningsih. 2008. Tumbuh Kembang Anak. Jakarta: EGC

Sofiani, A. 2011. Perbedaan Kenaikan Berat Badan Antara Bayi Umur 0-6 Bulan yang di Pijat Bayi dan yang Tidak Dipijat bayi di BPS Yohana Kota Semarang. Karya Tulis Ilmiah: Poltekkes Semarang

Sukanta, P. Okta. 2010. Pijat Akupresur Untuk Kesehatan. Penebur Plus: Jakarta

Unicef. 2011. UNICEF dan Uni Eropa bersama menangani masalah ketahanan gizi di Asia yang mengkhawatirkan. www.unicef.org

Widodo, Joko. 2012. Edukasi dan konsultasi sulit makan dan gangguan kenaikan berat badan. Jakarta: Picky Eaters And Grow Up Clinik.

Yuliana Amelia dkk. 2013. Perbedaan Berat Badan Bayi Usia 3-5 Bulan. Dipublikasikan di Jurnal Penelitian Kesehatan Suara Forikes, 2013, 2014, volume IV. No 4 hal 216- 219. ISSN 2086-3098

Zhen Huan Liu., Li-ting Cen. 2011. Effect Tui $\mathrm{Na}$ On Neurodevelopment in Premature Infant. Journal of Acupuncture and Tuia Science. Vol. 11, Issue 1, pp7-12. Shanghai Research Institute of Acupuncture and Meridian 